\title{
CURRÍCULO E O ENSINO DE GEOGRAFIA: ORIENTAÇÕES CURRICULARES E EDUCOPÉDIA NA SECRETARIA MUNICIPAL DE EDUCAÇÃO DO RIO DE JANEIRO
}

\author{
Curriculum and education of Geography: curricular orientations and Educopédia in the Municipal \\ Education of Rio de Janeiro
}

Renata Bernardo Andrade*

*Professora de geografia SME/RJ - prof.renata.geo@gmail.com.

\begin{abstract}
Resumo: O currículo escolar é um instrumento de formação do indivíduo, por meio de seus discursos, convergências e divergências: conceituais, metodológicas, pedagógicas, sociais e políticas organizam-se um determinado conhecimento, destacamos- o geográfico, tendo como premissa ler e interpretar o mundo. Assim, este trabalho objetiva um debate teórico sobre o papel do ensino de geografia por meio do uso da Educopédia com base na análise das orientações curriculares da Secretaria Municipal de Educação do Rio de Janeiro. A metodologia utilizada foi à análise de conteúdo da plataforma digital dos conteúdos de geografia e das Orientações Curriculares. Os resultados mostram que a organização curricular de conteúdos e os objetivos do ensino buscam ter eficiência nos resultados.
\end{abstract}

Palavras-chave: Ensino de geografia, Currículo, Orientações Curriculares e Educopédia.

\begin{abstract}
The school curriculum is an instrument of formation of the individual, through his discourses, convergences and divergences: conceptual, methodological, pedagogical, social and political that from it organizes certain knowledge. This knowledge, in which we highlight the geographic, has as premise to read and interpret the world through its physical-natural and human-social phenomena. Thus, this paper aims at a theoretical debate about the role of geography teaching through the use of Educopédia based on the analysis of the curricular guidelines of the Municipal Department of Education of Rio de Janeiro. The methodology used was content analysis of the digital platform of the contents of geography and the Curricular Guidelines. The results show that the curricular organization of contents, aims of teaching seeks to have efficiency in the results. It is observed as objectives set for the learning of the students to recognize, to observe and to identify the geographic elements, of specific contents, but not associated to the aspects of the quotidian.
\end{abstract}

Key-words: Geography Teaching, Curriculum, Curriculum Guidelines and Educopédia.

\section{Introdução}

O presente trabalho visa analisar a construção da Educopédia de Geografia articulada com Orientações Curriculares da Secretaria Municipal de Educação do Rio de Janeiro no ensino de geografia desenvolvido. 0 currículo escolar não é somente um discurso, mas é um artefato social que organiza a forma estrutural do ambiente escolar e, principalmente, o tipo de saber que se deseja transmitir.

Os conteúdos da geografia escolar devem ensinar aos alunos uma maneira de pensar o mundo geográfico, que os possibilitem aprender a ler a espacialidade diferencial, as origens 
naturais, sociais, políticas e econômicas da desigual produção do espaço. Estimular o olhar do aluno, para a compreensão do espaço como produto e produtor das relações existentes na sociedade e da sua forma de organização. As novas tecnologias de informação e comunicação tem se apresentado como tendência na educação em varias disciplinas, mas aqui em especial focaremos os conteúdos geográficos disposto na plataforma educacional Educopédia.

A metodologia empregada nesta pesquisa é qualitativa, com base na análise da página da plataforma digital, na Internet, e dos conteúdos de geografia de forma geral descritos. Assim, o foco do estudo a Orientação Curricular do Rio de Janeiro e a plataforma Educopédia, por meio da coleta dos dados se referem ao documento curricular e da página, na Internet; e, por fim, a análise do conteúdo dos mesmos.

Ao se pensar como analisar e interpretar a plataforma educacional Educopédia, a análise do conteúdo acaba sendo um elemento importante neste diálogo, pois o documento apresenta características que são próprias a ela. Ela faz com que sejam analisados a "fala" e os textos, imagens, ou seja, "ela se constitui um conjunto de métodos e de teorias que pretendem investigar quer o uso cotidiano da linguagem, quer a linguagem nos contextos sociais, desta forma interpretando as mensagens a serem compreendidas", MORAES (1999, p.13).

O texto está dividido em três seções: a primeira que destaca sobre do currículo escolar; a segunda sobre o currículo e o ensino de geografia e a terceira sobre as orientações curriculares e Educopédia no ensino de geografia na SME/RJ.

\section{Abordagens acerca do currículo escolar}

O tema sobre o currículo escolar aparece pela primeira vez, como objeto de estudo e pesquisa, na década de 1920, nos Estados Unidos, sendo o Bobbit (1918), o primeiro autor que escreveu sobre currículo num momento no qual diversas forças políticas, econômicas e culturais procuravam desenvolver a educação de massas para garantir que sua ideologia fosse garantida Silva (1999); Malta (2013). Bobbit (1918) propunha que a escola funcionasse como uma indústria sendo o currículo uma questão de organização dos conteúdos considerados relevantes ocorrendo de forma mecânica e burocrática.

Silva (1999) afirma que Bobbit, no livro "The curriculum" (1918) compreende o currículo escolar como um processo de racionalização de resultados educacionais, rigorosamente especificados e medidos. 0 modelo institucional dessa concepção de currículo é a fábrica. No currículo é preciso traçar planos, ter metas, saber os objetivos e saber fazê-los para que no fim sua "jornada" ou sua "trajetória" seja completa e satisfatória, ou seja, fazer o currículo é saber qual a sua intenção, de que forma construí-lo e para que fim.

Para Sacristán (2000, p.15) "definimos currículo descrevendo a concretização das funções da própria escola e a forma particular de enfocá-las num momento histórico e social determinado, para um nível de modalidade de educação, numa trama institucional". 0 currículo é um meio pelo qual a escola se organiza, propõe os seus caminhos e a orientação para a prática. Não podemos pensar uma escola sem pensar em seu currículo e em seus objetivos. Existem diversas concepções e conceituações de currículo em diferentes momentos históricos, mas Silva (1999) aponta como questão central que serve de pano de fundo para as teorias do currículo a de saber: Qual conhecimento deve ser ensinado?

Essa pergunta nos revela como os teóricos das teorias do currículo têm o interesse de analisar as concepções ideológicas e conceituais, além dos critérios de seleção dos documentos vigentes. Nas teorias do currículo, a pergunta "o quê?" Nunca é separada de

ParaOnde!?, Porto Alegre, v.10, n.2, p.36-44, 2018. Edição Especial com artigos publicados originalmente na XII ENANPEGE http://seer.ufrgs.br/paraonde 
outra importante pergunta: "O que os alunos devem se tornar?"

Atualmente, busca-se apresentar uma nova perspectiva de educação, não apenas com objetivos de transmissão de conteúdos, por isso entendemos que o currículo é cheio de intenções e significados, além de disputas de relações de poder, sobre aquilo que somos e em que nos tornamos.

O significado do currículo é orientar como a escola deve se organizar para estabelecer determinados parâmetros para pensar e estruturar as orientações político-pedagógicas, administrativas e sociais com o propósito de legitimar o papel da escola enquanto um espaço sócio- educativo- cultural.

Desta forma, todas as pessoas envolvidas na elaboração de um currículo, não o fazem de maneira neutra. Tornando, o currículo escolar impregnado de valores, ideologias, forças e interesses. Entender essa dinâmica é importante para o professor, uma vez que o currículo se operacionalizará durante a aula e em diversos espaços da escola. Assim a cada época o currículo se modifica de acordo com o poder vigente, com pensamento e tipo de estrutura escolar que a sociedade e o governo desejam.

\section{0 currículo e ensino de geografia}

Para pensar sobre um currículo é preciso responder algumas questões, privilegiando assim alguns conteúdos em relação a outros. Deste modo, esse movimento de questionar quais conteúdos relevantes devem ser aplicados à elaboração de um currículo de geografia. O que ensinar em geografia? É uma pergunta que deve ser feita pelos docentes desta disciplina, é importante ainda dentro de um viés da teoria crítica do currículo- se questionar sobre o por quê? Por que ensinar geografia? Por que devo ensinar este e não aquele conteúdo da geografia? É preciso ter clareza da diferença entre geografia acadêmica e a geografia escolar?É importante para que o professor de geografia da escola básica sabero propósito da geografia no ensino? O que se pretende ao ensinar geografia na escola básica?

A geografia escolar ainda é vista como uma disciplina enfadonha de memorização de determinadas informações geográficas tornando-se uma disciplina voltada para a simples descrição de mundo. Lacoste (2012) denomina geografia dos professores, o método de investigação positivista, que se organiza metodologicamente no modelo de naturezahomem-economia (N-H-E) apresentado por MOREIRA (2014). Uma geografia descritiva, com valorização do empírico como discurso pedagógico enciclopédico. Ou seja, "pela estruturação mecânica de fatos, fenômenos e acontecimentos divididos em aspectos físicos, aspectos humanos e aspectos econômicos [...]" (CAVALCANTI, 2013, p.20). Nas palavras de Lacoste (2012), a geografia é um conhecimento estratégico para determinações de poder, mas ocultado pela geografia escolar que não garante aos alunos a capacidade de ler as representações espaciais.

Para Castellar; Steferon (2015), a geografia na escola precisa superar a geografia dos professores, "estudar geografia é uma oportunidade para entendermos o mundo em que vivemos, visto que essa disciplina refere-se às ações humanas construídas em diferentes sociedades e lugares" (p.1). No currículo escolar, esta disciplina possibilita ao aluno desenvolver um raciocínio espacial, compreensão dos lugares em diferentes escalas, auxiliando-o a localizar e criar conexões entre os "lugares da superfície da Terra de forma criteriosa e com o devido rigor científico" (p. 1.).

Cavalcanti (2012) aponta a geografia enquanto uma forma de leitura da realidade, que pode ser alcançada por um conjunto de interrogações sobre os fenômenos do mundo, isto é,

ParaOnde!?, Porto Alegre, v.10, n.2, p.36-44, 2018. Edição Especial com artigos publicados originalmente na XII ENANPEGE http://seer.ufrgs.br/paraonde 
"questões elencadas como típicas da geografia - Onde? Por que nesse lugar? Como é esse lugar?" (p.135).

A geografia na escola não deve formar jovens geógrafos, o papel da geografia escolar é desenvolver capacidade de pensar teoricamente para analisar a realidade e a espacialidade dos fenômenos naturais e sociais, de forma crítica. Os conteúdos da geografia escolar devem ensinar aos alunos uma maneira de ver o mundo, ensinando um modo de pensar geográfico, que os possibilitem aprender a ler a espacialidade diferencial, as origens naturais, sociais, políticas e econômicas da desigual produção do espaço. Estimular o olhar do aluno para a compreensão do espaço como produto e produtor das relações existentes na sociedade e da sua forma de organização.

Baseado em um raciocínio geográfico, estabelecer conexões existentes entre as escalas, do local ao global retornando ao local, para poder aplicar uma leitura crítica a sua realidade. Cavalcanti (2012) aponta que os professores de geografia estão sempre procurando novas e diferentes formas de trabalhar e ensinar, novos materiais, novos recursos, novas metodologias. Entretanto os professores têm pouco espaço e tempo em sua jornada de trabalho para a reflexão no sentido de detectar suas dificuldades e conquistas. E que tais momentos podem ser considerados formação continuada, mas geralmente não é isso que acontece.

Segundo Cavalcanti (2012, p.142), "ensinar uma matéria depende não apenas de métodos didáticos, mas de outros tipos de métodos, como o método cientifico, os métodos da cognição e os métodos particulares das ciências". Portanto, o professor ao planejar uma aula precisa ter conhecimento prévio dos métodos científicos para selecionar uma linha metodológica: positivismo; fenomenologia ou dialética e saber também como epistemologicamente os alunos aprendem, e qual ou quais correntes de pensamento geográfico ele pretende seguir. Tendo essa concepção, o professor terá que mediar o objeto encaminhando um trabalho de abstrações e generalizações, utilizando diversos elementos e processos mentais, para além da simples memorização e/ou constatação das propriedades e qualidades do objeto. Para alcançar na geografia escolar um olhar crítico e estimular o pensamento do aluno para fazer uma análise sobre a realidade.

\section{Orientações curriculares e Educopédia no ensino de geografia na SME/RJ}

As Orientações Curriculares segundo a SME/RJ foram organizadas a partir de discussões realizadas com professores (as) da rede pública municipal de ensino, tendo como objetivo elencar conteúdos e objetivos que são centrais ao trabalho da Geografia Escolar.

A seleção dos conteúdos está relacionada ao tipo de ser humano que se quer formar e também é uma disputa de poder sobre o que se pode e quer ensinar. Cada contexto histórico caracteriza formas políticas e econômicas nas quais diferem as organizações curriculares de uma disciplina, bem como a escolha dos conceitos e conteúdos e a dinâmica escolar.

Ademais elenca-se um conjunto de "habilidades" consideradas como fundamentais pela SME/RJ à formação cidadã, com ênfase no domínio da linguagem cartográfica, gráfica, imagética. A SME/RJ ao se referir às habilidades (figura 1) já expressa uma concepção de matriz curricular baseada por competências e habilidades, compreendida por comportamentos mensuráveis e cientificamente controláveis. Ações executadas com base em habilidades, buscando indicadores de desempenho para avaliação, desconsiderando as relações sociais cotidianas dos alunos que são substituídas por competências técnicas de saberes especializados, LOPES (2008).

Para0nde!?, Porto Alegre, v.10, n.2, p.36-44, 2018. Edição Especial com artigos publicados originalmente na XII ENANPEGE http://seer.ufrgs.br/paraonde 


\begin{tabular}{|c|c|c|c|c|c|c|c|}
\hline \multicolumn{8}{|c|}{ ORIENTAÇŌES CURRICULARES PARA O ENSINO DE GEOGRAFIA - 6. } \\
\hline \multirow{2}{*}{ OBJETIVOS } & \multirow{2}{*}{ CONTEÚDOS } & \multirow{2}{*}{ HABILIDADES } & \multicolumn{4}{|c|}{ BIMESTRES } & \multirow{2}{*}{ SUGESTŌES } \\
\hline & & & $1 .^{\circ}$ & $2 .^{\circ}$ & $3 .^{\circ}$ & $4 .^{\circ}$ & \\
\hline $\begin{array}{l}\text { Reconhecer fenômenos } \\
\text { e processos } \\
\text { socioespaciais, } \\
\text { tomando como centrais } \\
\text { os conceitos de lugar e } \\
\text { paisagem. }\end{array}$ & $\begin{array}{l}\text { PAISAGEM: } \\
\text { municipio do Rio de } \\
\text { Janeiro estado do Rio } \\
\text { de Janeiro. }\end{array}$ & $\begin{array}{l}\text { Reconhecer elementos naturais } \\
\text { e humanizados presentes na } \\
\text { paisagem retratada em } \\
\text { iconografias ou observada em } \\
\text { trabalhos de campo. } \\
\text { Distinguir, em iconografias, } \\
\text { paisagens naturais e } \\
\text { humanizadas, urbanas e rurais. } \\
\text { Identificar os principais } \\
\text { elementos da paisagem da } \\
\text { cidade do Rio de Janeiro e do } \\
\text { estado do Rio de Janeiro, } \\
\text { retratada em iconografias ou } \\
\text { observada em trabalhos de } \\
\text { campo, tendo por base as } \\
\text { vivências e os conteúdos } \\
\text { adquiridos pelos alunos de } 4 .^{\circ} \\
\text { e } 5 .^{\circ} \text { anos. } \\
\text { Reconhecer o espaço } \\
\text { geográfico como resultado da } \\
\text { interação das sociedades com a } \\
\text { natureza. } \\
\text { Reconhecer o papel das } \\
\text { sociedades na transformação } \\
\text { do espaço geográfico, } \\
\text { percebendo-se com agente } \\
\text { ativo da construção do seu } \\
\text { próprio espaço. }\end{array}$ & $\mathrm{x}$ & & & & $\begin{array}{l}\text { Usar o site "ARMAZENZINHO" da Prefeitura } \\
\text { do Rio de Janeiro para buscar informaçōes } \\
\text { sobre cada bairro da cidade, especialmente } \\
\text { daquelas areas habitadas pelos alunos. } \\
\text { Pedir para cada aluno pesquisar sobre um } \\
\text { bairro da cidade que ele não conheça, mas que } \\
\text { tenha muita curiosidade de visitar. } \\
\text { Utilizar o google maps a fim de reconhecer os } \\
\text { municipios da Região Metropolitana, } \\
\text { estimulando o aluno a conhecer virtualmente } \\
\text { um deles. Criar painéis fotográficos com o } \\
\text { bairro ou a comunidade em que o aluno reside, } \\
\text { o bairro que gostaria de visitar e a cidade } \\
\text { vizinha que gostaria de conhecer. } \\
\text { Sugerir a montagem de um mural que expresse } \\
\text { a diversidade de identidades, presentes no } \\
\text { espaço da cidade do Rio de Janeiro. É de suma } \\
\text { importância o aluno relacionar a representaçăo } \\
\text { espacial à realidade social. } \\
\text { Fazer um levantamento sobre o papel da } \\
\text { Prefeitura, do Governo Estadual e das } \\
\text { Associaçőes comunitárias no dia a dia do } \\
\text { aluno: quem é responsável pela coleta de lixo, } \\
\text { pela segurança pública, pela educação, pela } \\
\text { saúde, por representar os anseios dos } \\
\text { moradores de uma comunidade etc. }\end{array}$ \\
\hline
\end{tabular}

Figura 1: Quadro das orientações curriculares da SME/RJ

Fonte: SME/RJ

Analisando as orientações curriculares da SME/RJ, observa-se que predomina os elementos como objetivos, competências e habilidades voltadas para o saber-fazer e reconhecemos os conteúdos da geografia organizados de forma tradicional. Observa-se que os alunos precisam reconhecer observar e identificar os elementos geográficos, de conteúdos específicos, mas não associados aos aspectos do cotidiano. As sugestões de trabalho em sala para o professor aparentemente apresentam relação com o cotidiano do aluno, mas apenas de forma parcial como reconhecimento das diversidades e uso de tecnologias sem a crítica ao poder hegemônico estabelecido.

0 ensino de geografia ainda é caracterizado de acordo com os interesses de Governo e de suas Políticas Públicas para a Educação e os conteúdos não relacionados à realidade e nem a qualquer crítica relacionada ao Estado. As reformulações dos currículos pelo Estado são realizadas conforme o contexto de cada época, na atualidade vive-se o contexto neoliberal com o espaço vivido e produzido pela sociedade capitalista. Couto (2014) relata que as atuais políticas educacionais reproduzem o processo de expansão com precarização da educação pública brasileira, a atual conjuntura neoliberal visualizada na finalidade de formação do trabalhador flexível e de consumidores (finalidade da educação), nas políticas de currículo, na avaliação externa, em ações de controle da escola/professores, na política produtivista da meritocracia, de flexibilidade dos saláriose condições de trabalho, visando otimizar custos em 
função de metas burocráticas.

\begin{abstract}
Deste conjunto de políticas neoliberais se desenvolvem várias ações. Para despertar o interesse dos alunos, propõe-se que o processo pedagógico se organize a partir de sua experiência cotidiana e da resolução de problemas, mas não dos diferentes conteúdos das disciplinas escolares, resultando em certa confusão entre currículo organizado por competências e habilidades e o currículo centrado nos objetivos e conteúdos/temáticas das disciplinas escolares. (COUTO, 2014, p.254).
\end{abstract}

A SME/RJ organiza apostilas e provas bimestrais de português, matemática e ciências para todos os alunos da rede. Anteriormente existiam também apostilas de geografia e história, mas foram extintas devido à reivindicação dos professores para usar seus materiais ou ao corte de verbas, pois essas disciplinas são consideradas secundárias.

Segundo Costin (Secretaria de educação) iniciou-se em 2010, um novo movimento que parte da SME/RJ, objetivando oferecer um processo didático inovador, a proposta de implantação de uma escola que oferta oportunidade de o aluno acessar e trabalhar a construção de seu conhecimento. Para isso, foi criado um projeto de aulas interativas a Educopédia.

Conforme, observado no site da plataforma a Educopédia foi formatada por professores selecionados da própria rede, considerando as Orientações Curriculares do Município do Rio de Janeiro. 0 projeto consiste em atividades que incluem temas/conteúdos, com as respectivas competências, divididas em 32 aulas digitais, por disciplinas, correspondentes às semanas do ano letivo (figura 2). Vídeos, animações, imagens, textos, podcasts, quizzese jogos estão inseridos nas atividades, seguindo um roteiro pré-definido em consonância com teorias metacognitivas. 0 material educativo online é disponibilizado para alunos e professores da rede pública de ensino da cidade, que podem consultar essas informações de qualquer computador e a qualquer hora, através do endereço eletrônico.

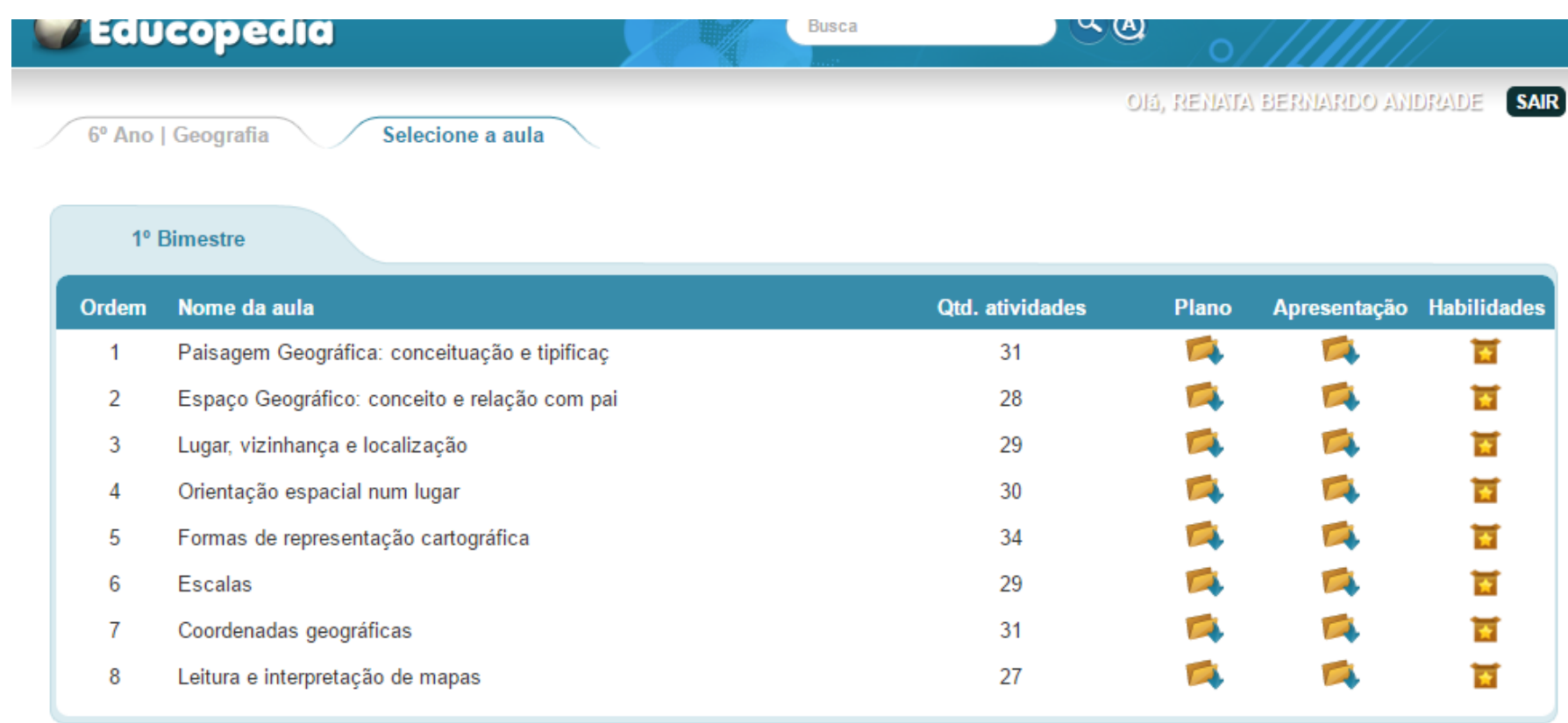

\title{
Figura 2: Conteúdo do Educopédia
}

Fonte: www.educopedia.com.br 
A apresentação da plataforma Educopédia representa uma nova roupagem tecnológica das orientações curriculares da SME/RJ, pois permanece baseada em habilidades e competências e objetivos descritivos dos conteúdos geográficos (figura 3). Com mais ilustrações, filmes e utilizando a internet e o computador ou projetor com quadro. Mas ainda sem nenhuma relação imediata com o cotidiano dos alunos ou gerando uma crítica às desigualdades sociais provocadas pelo sistema capitalista.

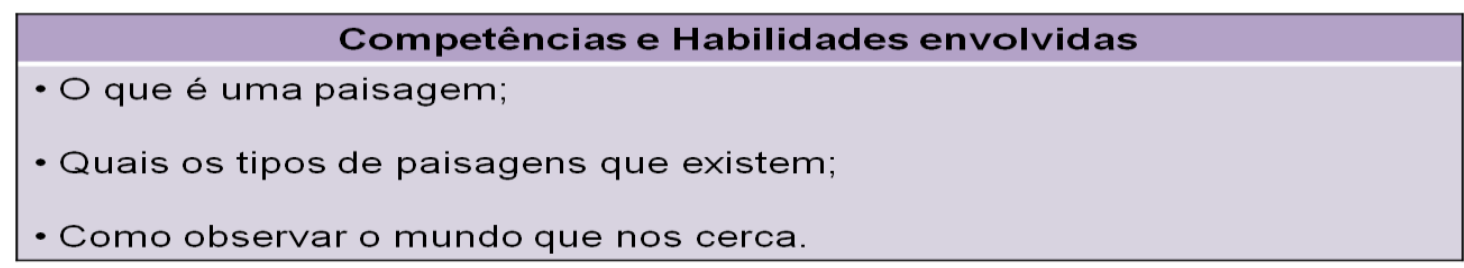

\section{Referencial Teórico}

BRASIL. Ministério da Educação e do Desporto, Secretaria de Educação Fundamental. Parâmetros curriculares nacionais: Ensino de quinta à oitava sérieGeografia. Brasília: MEC/SEF, 1998.

http://www.geograficas.cfh.ufsc.br/arquivo/ed06/ed06 art06.pdf

http://www.ceg.ul.pt/finisterra/numeros/2001-72/72 04.pdf

http://www.editorapositivo.com.br/ecobox/home-restrita/plano-de-aula/leiturageografia-volumes. html?newsID=7492b01da657401c9895720ff4488153

\section{Figura 3: Plano de aula disponibilizado na Educopédia para os professores}

Fonte: $\underline{w w w . e d u c o p e d i a . c o m . b r}$

Com relação ao conteúdo geográfico, continua apresentando o padrão N-H-E descrito por MOREIRA (2014). Uma geografia descritiva, com valorização do empírico (observação, identificação, caracterização) antes da teoria, e acontecimentos divididos em aspectos físicos, aspectos humanos e aspectos econômicos, que vêm se arrastando como discurso pedagógico, enciclopédico.0 avanço da reflexão e dos conhecimentos geográficos para superar esse empirismo de tradição da área contribui para colocar novos elementos da reflexão no campo da didática e da metodologia do ensino de geografia.

Entender o papel da escola e do currículo na formação da sociedade é importante para definir quais caminhos metodológicos devem ser seguidos durante a prática de ensino. Sendo assim, o que difere a escola da família e de outros espaços de educação? Segundo Young (2007), na escola existe a garantia de acesso ao conhecimento poderoso, "esse conceito não se refere a quem tem mais acesso ao conhecimento ou quem o legitima [...], refere-se ao que o conhecimento pode fazer, como por exemplo, fornecer explicações confiáveis ou novas formas de se pensar a respeito do mundo." (YOUNG, 2007, p. 1294).

Mas, qual visão de mundo pretende-se desenvolver ao se ensinar geografia? Segundo Cavalcanti (2013), a escola tem tido como principal função o ensinamento da lógica formal, baseado no método da ciência moderna, por um caminho que percorre do concreto ao abstrato. A proposta de substituição do modelo de escola (e de geografia na escola) que ensine nos moldes da lógica formal por uma que construa um raciocínio dialético, em que o aprendizado é entendido como fruto de um processo de contradições entre saberes prévios e novos saberes. Uma prática de ensino de geografia que considere os saberes prévios e os saberes locais dos alunos, suas representações sociais e suas "práticas sociais mediadas pelas imposições espaciais" Couto (2010, p.110) em outras palavras, suas práticas espaciais.

É preciso que o processo de ensino-aprendizagem comece na realidade dos alunos e

Para0nde!?, Porto Alegre, v.10, n.2, p.36-44, 2018. Edição Especial com artigos publicados originalmente na XII ENANPEGE http://seer.ufrgs.br/paraonde 
retorne para a mesma, mas como realidade conceitualmente pensada. Isso por que os conceitos trabalhados pela geografia, como espaço, lugar, paisagem, território, região, dentre outros, fazem parte do cotidiano das pessoas. A aprendizagem dos conteúdos/conceitos deve ser condição para que se formule uma resposta ao problema proposto, que possua valor sócio-cultural e espacial real e ao mesmo tempo se relacione com os conteúdos do ensino. Desta forma, à geografia caberia a função de ampliar o processo de letramento, próprio da escola fundamental, na medida em que desenvolve a alfabetização geográfica, isto é, a apropriação dos sentidos do mundo pelos conteúdos e conceitos da geografia.

\section{Considerações Finais}

Assim, as Orientações Curriculares apresentam então duas matrizes curriculares, resultando em certa confusão entre currículo organizado por competências e habilidades, e o currículo centrado nos objetivos e conteúdos/temáticas das disciplinas escolares, baseado em Lopes (2008).

Analisamos ainda os elementos predominantes como objetivos, competências e habilidades voltadas para o saber-fazer e reconhecer conteúdos da geografia organizados de forma tradicional de acordo com Malta (2013). Podemos resumir a organização curricular a partir de conteúdos, objetivos e ensino destes de forma a ter eficiência nos resultados.

Observam-se como objetivos traçados para a aprendizagem dos alunos é reconhecer, observar e identificar os elementos geográficos, de conteúdos específicos, mas não associados aos aspectos do cotidiano.

As sugestões de trabalho em sala para o professor aparentemente apresentam relação com o cotidiano do aluno, mas apenas de forma parcial embora com uma roupagem e discurso moderno ainda é tradicional,apenaspara o reconhecimento das diversidades e uso de tecnologias, sem a criticar ao poder hegemônico estabelecido.

\section{Referências}

CASTELLAR, Sonia Maria Vanzella; Steferon, Daniel Luiz. A Ciência Geográfica na escola: pressupostos de um currículo escolar fundamentado no conhecimento disciplinar. Uni-pluri (Medellin), v. 15, pp. 11-118, 2015.

CAVALCANTI, Lana de Souza. O Ensino de Geografia na Escola. Campinas, SP: Papirus, 2012.

COSTIN, Claudia. Apresentação da plataforma Educopédia. Disponível em http://www.educopedia.com.br/SobreEducopedia.aspx. Acessado em março de 2015.

COUTO, Marcos Antonio Campos. Ensinar a geografia ou ensinar com a geografia?Revista Terra Livre, São Paulo, SP, ano 26, v.1, n. 34, pp. 1-281, 2010.

. Práticas educativas na geografia que se ensina na escola pública brasileira. In: FERNANDEZ CASO, Maria Victoria; GUEREVICH, Raquel (org.). Didáctica de la geografía. Prácticas escolares y formación de profesores. 1ed.Ciudad Autónoma deBuenos Aires: INDEGEO/REDLADGEO/Ed. Biblos, 2014, v. 1, pp. 251-269.

LOPES, Alice Ribeiro Casimiro. Políticas de integração curricular. Rio de Janeiro: EdUERJ, 2008.

ParaOnde!?, Porto Alegre, v.10, n.2, p.36-44, 2018. Edição Especial com artigos publicados originalmente na XII ENANPEGE http://seer.ufrgs.br/paraonde 
MALTA, Shirley Cristina Lacerda. Uma abordagem sobre currículo e teorias afins visando à compreensão e mudança. Revista Espaço do Currículo (Online), v. 6, pp. 340-354, 2013.

MORAES, Roque. Análise de conteúdo. Revista Educação, Porto Alegre, v. 22, n. 37, pp. 7-32, 1999.

ORIENTAÇÕES CURRICULARES SME/RJ, 2016. Disponível em http://www.rioeduca.net/blogViews.php?id=5265. Acessado em março de 2016.

RIO DE JANEIRO. Secretaria Municipal de Educação. Núcleo Curricular Básico Multieducação. Rio de Janeiro, 1996.

SILVA, Tomaz Tadeu da (org). Teoria do currículo. In: Documentos de identidade: uma introdução às teorias do currículo. Belo Horizonte: Autêntica, 1999, pp. 11-17.

YOUNG, Michael. Para que serve as escolas? Educ. Soc., Campinas, vol. 28, n. 101, set./dez. pp. 1287-1302, 2007. Disponível em http://www.scielo.br/pdf/es/v28n101/a0228101.pdf. Acessado em março de 2016. 